\title{
Structural and Defect Properties of $\operatorname{LiTi}_{2}\left(\mathrm{PO}_{4}\right)_{3}$
}

\author{
Raveena Sukumar ${ }^{1 \mathbb{D}}$, Poobalasuntharam Iyngaran ${ }^{1 \mathbb{D}}$, Navaratnarajah Kuganathan ${ }^{2, *}$ (i) \\ 1 Department of Chemistry, University of Jaffna, Sir Pon Ramanathan Road, Thirunelvely, Jaffna, Srilanka \\ 2 Department of Materials, Imperial College London, London, SW7 2AZ, UK \\ * Correspondence: n.kuganathan@imperial.ac.uk;
}

Scopus Author ID 14324923800

Received: 5.01.2021; Revised: 28.01.2021; Accepted: 1.02.2021; Published: 8.02.2021

\begin{abstract}
LiTi}_{2}\left(\mathrm{PO}_{4}\right)_{3}$ is an attractive electrolyte material in Li-ion batteries' application due to its high ionic conductivity and high chemical stability. Here we employ atomistic simulation based on the classical pair potentials to examine the intrinsic defect processes, Li-ion migration, and solution of various dopants in $\mathrm{LiTi}_{2}\left(\mathrm{PO}_{4}\right)_{3}$. The Li-Frenkel $(0.73 \mathrm{eV})$ is calculated to be the most favorable defect energy process ensuring the formation of $\mathrm{Li}$ vacancies required for the vacancy-assisted Li-ion migration. Long-range three-dimensional lithium vacancy migration was observed with a low activation energy of $0.36 \mathrm{eV}$, inferring fast Li-ion diffusion. The most favorable isovalent dopants on the $\mathrm{Li}$ and $\mathrm{Ti}$ sites are $\mathrm{Na}$ and $\mathrm{Si}$, respectively. Li interstitials' formation in these materials is favored by doping of Ga on the Ti site. This engineering strategy can be of interest to improve the capacity of $\operatorname{LiTi}_{2}\left(\mathrm{PO}_{4}\right)_{3}$.
\end{abstract}

Keywords: $\mathrm{LiTi}_{2}\left(\mathrm{PO}_{4}\right)_{3}$; elecrtrolyte; defects; diffusion; dopants.

(C) 2021 by the authors. This article is an open-access article distributed under the terms and conditions of the Creative Commons Attribution (CC BY) license (https://creativecommons.org/licenses/by/4.0/).

\section{Introduction}

Phosphate based materials are of great interest in the development of rechargeable $\mathrm{Li}$ (or $\mathrm{Na}$ ) ion batteries, catalysts, and optical devices due to their structural stability provided by phosphate $\left(\mathrm{PO}_{4}\right)^{3-}$ tetrahedral units [1-4]. Commercial Li-ion battery technology has been using olivine $\mathrm{LiFePO}_{4}$ as a conventional cathode material for the last thirty years [2,5-8]. A considerable experimental and theoretical research activity has been devoted to developing olivine $\mathrm{LiFePO}_{4}$ and other phosphate-based materials to prepare electrode materials for rechargeable Li-ion batteries [8,9$12]$.

$\mathrm{LiTi}_{2}\left(\mathrm{PO}_{4}\right)_{3}(\mathrm{LTP})$ has been proposed as a candidate electrolyte material in the application of Li-ion batteries due to its high Li-ion conductivity [13]. Electrochemical conductivity experiments together with ${ }^{7} \mathrm{Li}$ NMR spectroscopy show that $\mathrm{Li}^{+}$conduction is high in the asprepared LTP [13]. A molecular dynamics simulation study carried out by Nuspl shows that the activation energy of lithium-ion migration is $28.95 \mathrm{kJmol}^{-1}(0.30 \mathrm{eV})$, inferring fast ion conduction [14]. A first-principles study was applied to look at the diffusion properties of LTP and its derivatives. It was concluded that the activation energy of Li-ion diffusion is $0.41 \mathrm{eV}$ and the substitution of Ti atoms leads to structural changes and diffusion of $\mathrm{Li}$ ions [15]. The effect of $\mathrm{Ga}$ substitution on the Ti site was studied by Liang et al. [16], and improved conductivity was noted compared with pure LTP. Though a few studies on the diffusion of $\mathrm{Li}^{+}$ions and the electrochemical studies are available, experimental or theoretical reports on the intrinsic defects and solution of dopants are not available in the literature. While intrinsic defects influence the electrochemical behavior of a material, the thermal, mechanical, and electrical properties are dominated by dopants. 
In this study, material modeling based on the classical pair- potentials was used to examine the intrinsic defects, diffusion of Li ions, and dopants' solution in LTP. This technique has been successfully applied to various ionic oxide materials in previous theoretical studies, including Liion battery and solid oxide fuel cell materials [8,9,17-21].

\section{Computational Methods}

All calculations were performed using a classical pair-wise potential simulation code GULP (General Utility Lattice Program) [22]. Interactions between ions were modeled using long-range (Coulombic) and short-range (Pauli repulsion and van der Waals attraction) forces. The Buckingham potentials (Table 1)[23-26] were used to describe Short-range repulsive forces. Structural relaxations were carried out using the Broyden-Fletcher-Goldfarb-Shanno (BFGS) algorithm [27]. In all relaxed configurations, forces on all atoms were smaller than $0.001 \mathrm{eV} / \AA$. The Mott-Littleton method was used to model point defects and migrating ions [28]. Lithium-ion migration was calculated by considering seven interstitial points with equal intervals between neighbor lithium sites. Defect energies of migrating ions at seven points along the diffusion path were calculated. The mid-point between two adjacent $\mathrm{O}$ vacancy sites was used as the defect calculation center to reduce the systematic errors. The energy difference between the maximum local energy associated with the saddle point along this diffusion path and the lowest Li vacancy formation energy is calculated and reported as activation energy. In this method, ions are treated as spherical shapes with full charge at the dilute limit. Therefore, it is expected that defect energies will be overestimated. However, the trend in relative energies will be consistent [29].

\section{Results and Discussion}

\subsection{Crystal structure of $\operatorname{LiTi}_{2}\left(\mathrm{PO}_{4}\right)_{3}$.}

The crystal structure of LZP exhibits a trigonal crystallographic structure with space group $R \overline{3} c$ (lattice parameters $\mathrm{a}=\mathrm{b}=8.5173 \AA, \mathrm{c}=20.8595 \AA, \alpha=\beta=90.0^{\circ}, \gamma=120^{\circ}$ ) as reported by Redhammer et al. [30]. Figure 1 shows the crystal structure and P's chemical environment (forming a tetrahedral unit with adjacent four oxygen atoms) and $\mathrm{Ti}$ (forming an octahedral unit with adjacent six oxygen atoms). The quality of the Buckingham potentials (Table 1)[23-26] used in this study was validated by performing a geometry optimization calculation on the crystal structure of LZP. An excellent agreement between the calculated and experimental values was observed, indicating the efficacy of the potential parameters (Table 2).

Table 1. Buckingham potential parameters [23-26] used in the classical simulations of LTP. Two-body [ $\Phi_{i j}\left(r_{i j}\right)$ $=A_{i j} \exp \left(-r_{i j} / \rho_{i j}\right)-C_{i j} / r_{i j}{ }^{6}$, where $\mathrm{A}, \rho$, and $\mathrm{C}$ are parameters which were selected carefully to reproduce the

\begin{tabular}{c|c|c|c|c|c}
\multicolumn{7}{c}{ Interaction } & $\boldsymbol{A} / \mathbf{e V}$ & $\boldsymbol{\rho} / \AA$ & $\mathbf{Y} / \mathbf{e}$ & $\mathbf{K} / \mathbf{e V} \cdot \AA^{-\mathbf{2}}$ \\
\hline $\mathrm{Li}^{+}-\mathrm{O}^{2-}$ & 632.1018 & 0.2906 & 0.00 & 1.00 & 99999 \\
\hline $\mathrm{Ti}^{4+}-\mathrm{O}^{2-}$ & 5111.7 & 0.2625 & 0.00 & -0.10 & 314.0 \\
\hline $\mathrm{P}^{5+}-\mathrm{O}^{2-}$ & 1273.42017 & 0.32272 & 0.000 & 5.00 & 99999 \\
\hline $\mathrm{O}^{2-}-\mathrm{O}^{2-}$ & 22764.00 & 0.1490 & 20.37 & -2.00 & 15.52
\end{tabular}




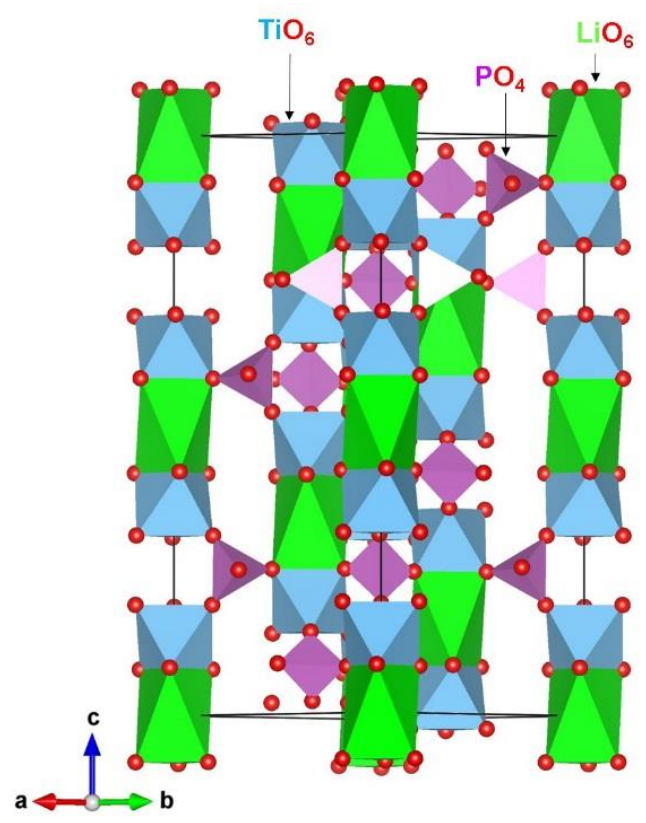

Figure 1. Crystal structure of rhombohedral LTP.

Table 2. Comparison between calculated and experimental lattice parameters of LTP.

\begin{tabular}{c|c|c|c} 
Parameter & Calculated & Experiment [30] & $|\Delta| \mathbf{( \% )}$ \\
\hline $\mathrm{a}=\mathrm{b}(\AA)$ & 8.4938 & 8.5173 & 0.28 \\
\hline $\mathrm{c}(\AA)$ & 21.1528 & 20.8595 & 1.41 \\
\hline$\alpha=\beta\left(^{\circ}\right)$ & 90.0 & 90.0 & 0.00 \\
\hline$\gamma\left({ }^{\circ}\right)$ & 120.0 & 120.0 & 0.00 \\
\hline $\mathrm{V}\left(\AA^{3}\right)$ & 1321.60 & 1310.50 & 0.85
\end{tabular}

\subsection{Intrinsic defects.}

The electrochemical properties of a material can be influenced by intrinsic defects. Thus, a series of point defects (vacancies and interstitials) were considered. Then they were combined to calculate Schottky and Frenkel energies. Anti-site defect in which $\mathrm{Li}$ and $\mathrm{Ti}$ exchange their positions were also considered. We describe the Schottky, Frenkel, and anti-site defects by the following defect reaction equations using Kröger-Vink notation [31].

Li Frenkel: $\mathrm{Li}_{\mathrm{Li}}^{\mathrm{X}} \rightarrow V_{\mathrm{Li}}^{\prime}+\mathrm{Li}_{\mathrm{i}}^{\circ}$

Ti Frenkel: $\mathrm{Ti}_{\mathrm{Ti}}^{\mathrm{X}} \rightarrow V_{\mathrm{Ti}}^{\prime \prime \prime \prime}+\mathrm{Ti}_{\mathrm{i}}^{\cdots \cdots}$

P Frenkel: $\mathrm{P}_{\mathrm{P}}^{\mathrm{X}} \rightarrow V_{\mathrm{P}}^{\prime \prime \prime \prime \prime}+\mathrm{P}_{\mathrm{i}}^{\cdots \cdots}$

O Frenkel: $\mathrm{O}_{\mathrm{O}}^{\mathrm{X}} \rightarrow V_{\mathrm{O}}^{\bullet \bullet}+\mathrm{O}_{\mathrm{i}}^{\prime \prime}$

Schottky: $\mathrm{Li}_{\mathrm{Li}}^{\mathrm{X}}+2 \mathrm{Ti}_{\mathrm{Ti}}^{\mathrm{X}}+3 \mathrm{P}_{\mathrm{P}}^{\mathrm{X}}+12 \mathrm{O}_{\mathrm{O}}^{\mathrm{X}} \rightarrow V_{\mathrm{Li}}^{\prime}+2 V_{\mathrm{Ti}}^{\prime \prime \prime \prime}+3 V_{\mathrm{P}}^{\prime \prime \prime \prime \prime}+12 V_{\mathrm{O}}^{\bullet \bullet}+\operatorname{LiTi}_{2}\left(\mathrm{PO}_{4}\right)_{3}$

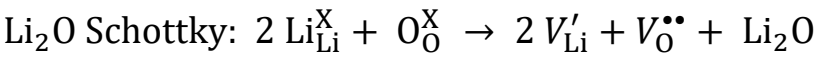

$\mathrm{TiO}_{2}$ Schottky: $\mathrm{Ti}_{\mathrm{Ti}}^{\mathrm{X}}+2 \mathrm{O}_{\mathrm{O}}^{\mathrm{X}} \rightarrow V_{\mathrm{Ti}}^{\prime \prime \prime \prime}+2 V_{\mathrm{O}}^{\ddot{*}}+\mathrm{TiO}_{2}$

$\mathrm{Li} / \mathrm{Ti}$ antisite (isolated): $\mathrm{Li}_{\mathrm{Li}}^{\mathrm{X}}+\mathrm{Ti}_{\mathrm{Ti}}^{\mathrm{X}} \rightarrow \mathrm{Li}_{\mathrm{Ti}}^{\prime \prime \prime}+\mathrm{Ti}_{\mathrm{Li}} \ddot{ }$

$\mathrm{Li} / \mathrm{Ti}$ antisite (cluster): $\mathrm{Li}_{\mathrm{Li}}^{\mathrm{X}}+\mathrm{Ti}_{\mathrm{Ti}}^{\mathrm{X}} \rightarrow\left\{\mathrm{Li}_{\mathrm{Ti}}^{\prime \prime \prime}: \mathrm{Ti}_{\mathrm{Li}}^{\bullet \bullet}\right\}^{\mathrm{X}}$

Figure 2 reports the defect reaction energies. The Li Frenkel is the lowest energy defect process with the defect energy of $0.73 \mathrm{eV}$, ensuring the formation of $\mathrm{Li}$ vacancies required for the vacancy mediated Li-ion diffusion. Furthermore, low Frenkel energies will ensure the formation of a high concentration of vacancies and interstitials, leading to the loss of crystal structure. The second most favorable defect is $\mathrm{Li}_{2} \mathrm{O}$ Schottky. However, the vacancies' concentration arising from these defects is not significant as this process is endothermic by 
$3.59 \mathrm{eV}$. Other Frenkel and Schottky defects are highly endoergic, meaning that they are not significant at room temperature. The Li-Ti anti-site defect cluster energy is calculated to be $6.21 \mathrm{eV}$. In this defect process, both $\mathrm{Li}^{+}$and $\mathrm{Ti}^{4+}$ ions will exchange their positions simultaneously. Its isolated form exhibits high defect energy of $9.16 \mathrm{eV}$. High anti-site defect energies are due to the charge mismatch between $\mathrm{Li}^{+}$and $\mathrm{Ti}^{4+}$. The energy difference between these two forms of anti-site defect energies is the binding energy $(-2.95 \mathrm{eV})$, inferring the unstable nature of isolates defects $\left(\mathrm{Li}_{\mathrm{Ti}}^{\prime \prime \prime}+\mathrm{Ti}_{\mathrm{Li}}^{\bullet \bullet \bullet}\right)$ and the preference of forming defect cluster

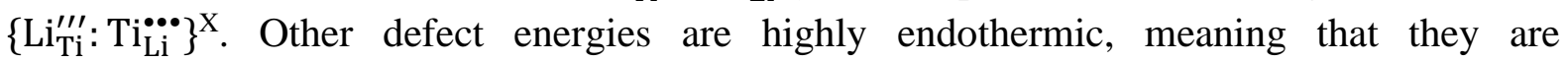
thermodynamically unfavorable.

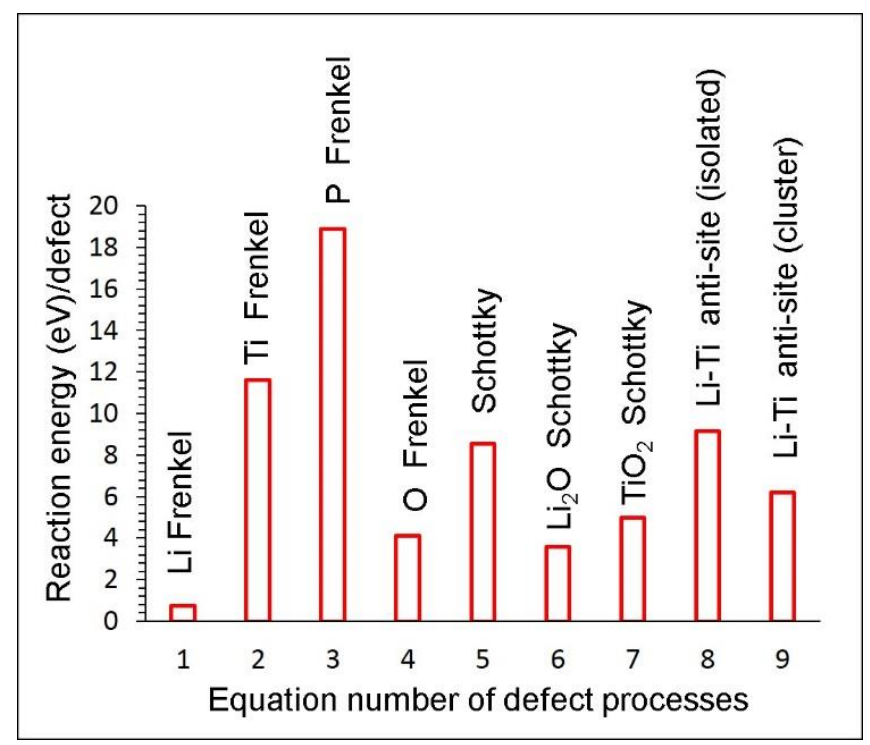

Figure 2. Defect energies for different defect processes.

\subsection{Diffusion of Li-ions.}

To design an efficient battery, an electrolyte material with high ionic conductivity and low activation energy is necessary. As the diffusion of Li-ions in this material can be of interest in Liion batteries' application, we calculated the Li-ion diffusion pathways together with activation energies.

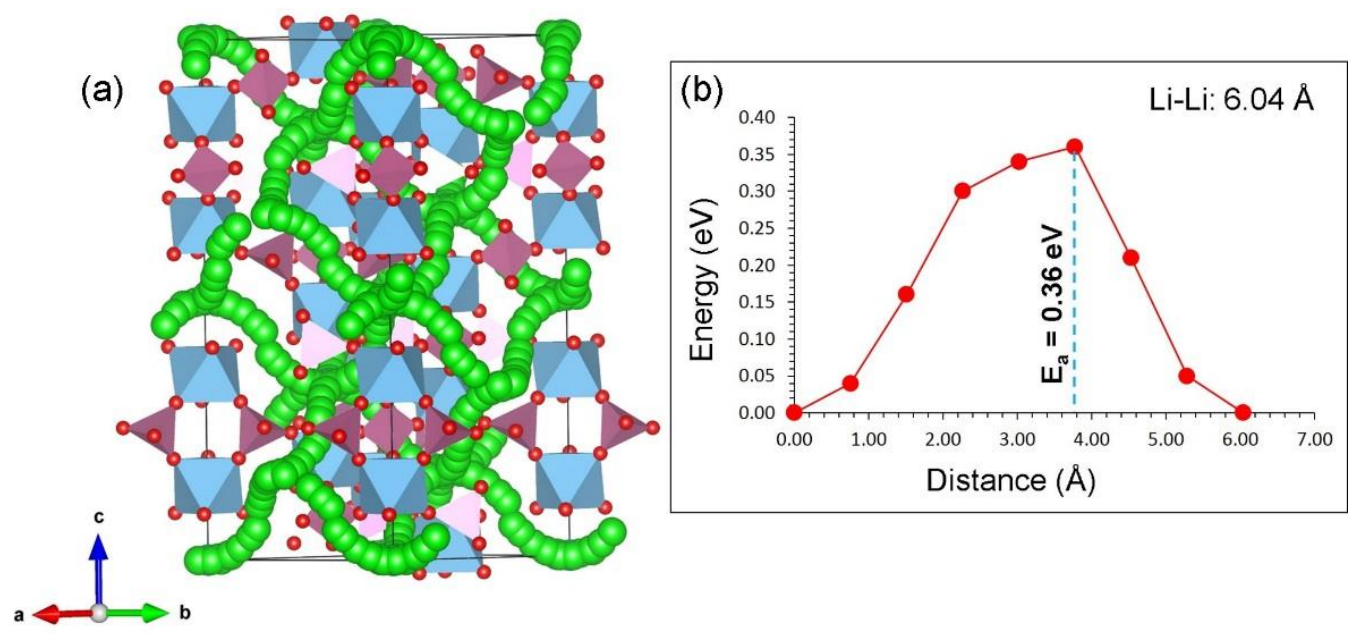

Figure 3. (a) Long-range Li vacancy migration path considered using local Li hops; (b) energy profile diagram for a local Li hop with its activation energy.

In general, the experimental investigation of diffusion pathways is challenging. The classical pair of potential based simulations can be used to calculate diffusion pathways and their 
activation energies. In previous simulation studies [8,9, 32-35], a variety of ionic materials have been considered to calculate diffusion pathways together with activation energies. For example, a simulation study based on the classical pair potentials by Fisher et al. [9] reproduced the experimentally determined $\mathrm{Li}$-ion diffusion pathway in $\mathrm{LiFePO}_{4}$ [36].

A possible local Li hop with a jump distance of $6.04 \AA$ was identified. Its activation energy was calculated to be $0.36 \mathrm{eV}$ (Figure 3). This shows that the diffusion of Li-ions in this material is fast. A three-dimensional long-range diffusion pathway was constructed using this local hop, as shown in Figure 3a. The activation energy $(0.36 \mathrm{eV})$ calculated in this study (Figure $3 \mathrm{~b})$ is in good agreement with the experimental value of $0.36 \mathrm{eV}$ [16] and other theoretical values of $0.30 \mathrm{eV}$ [14] and $0.41 \mathrm{eV}$ [15].

\subsection{Solution of dopants.}

Doping of appropriate dopants with different size or charge compared to the host atoms can tailor the properties of a material. Here we consider various isovalent and aliovalent dopants to screen and predict the promising dopants that can be considered for experiments. Solution energies were calculated using appropriate charge-compensating defects and lattice energies. Buckingham potentials used for dopants in this study are reported in the supplementary information (refer to Table S1).

Some monovalent dopants $(\mathrm{M}=\mathrm{Na}, \mathrm{K}$, and $\mathrm{Rb})$ on the Li site were first considered. Solution energies were calculated using the following reaction equation.

$\mathrm{M}_{2} \mathrm{O}+2 \mathrm{Li}_{\mathrm{Li}}^{\mathrm{X}} \rightarrow 2 \mathrm{M}_{\mathrm{Li}}^{\mathrm{X}}+\mathrm{Li}_{2} \mathrm{O}$

Exoergic solution energies were calculated for $\mathrm{Na}$ and $\mathrm{K}$. The most favorable dopant is the $\mathrm{Na}$ with exothermic solution energy of $-0.79 \mathrm{eV}$, suggesting that the synthesis of $\mathrm{Li}_{1}$ ${ }_{x} \mathrm{Na}_{x} \mathrm{Ti}_{2}\left(\mathrm{PO}_{4}\right)_{3}$ is possible. Exothermic solution energy for $\mathrm{K}(-0.20 \mathrm{eV})$ indicates that the experimental preparation of K-doped LTO is also worth trying. Doping of $\mathrm{Rb}$ exhibits endothermic solution energy, meaning that it is an unfavorable dopant (refer to Figure 4). Solution energy increases with the dopant size.

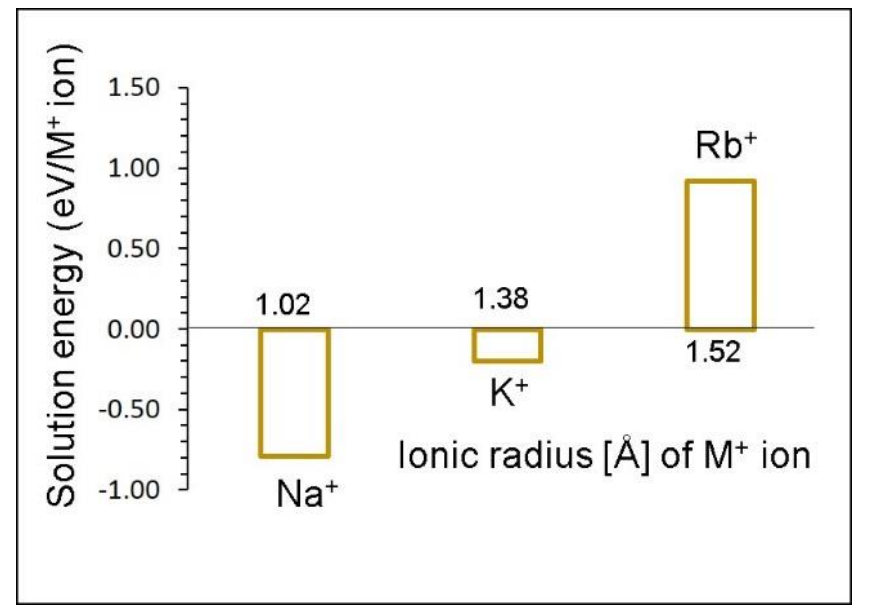

Figure 4. Solution energy of $\mathrm{M}_{2} \mathrm{O}(\mathrm{R}=\mathrm{Na}, \mathrm{K}$, and $\mathrm{Rb})$ with respect to the $\mathrm{M}^{+}$ionic radius in LTP.

A range of trivalent dopants ( $\mathrm{Al}, \mathrm{Co}, \mathrm{Ga}, \mathrm{Mn}, \mathrm{Sc}, \mathrm{In}, \mathrm{Yb}, \mathrm{Y}$, and $\mathrm{Gd}$ ) was considered on the Ti site to introduce Li interstitials in the lattice. The capacity of LTP can be increased by doping of trivalent dopants on the Ti site. This dopant process will lead to the formation of $\mathrm{Li}$ interstitials as described by the following equation.

$\mathrm{M}_{2} \mathrm{O}_{3}+2 \mathrm{Ti}_{\mathrm{Ti}}^{\mathrm{X}}+\mathrm{Li}_{2} \mathrm{O} \rightarrow 2 \mathrm{M}_{\mathrm{Ti}}^{\prime}+2 \mathrm{Li}_{\mathrm{i}}^{\bullet}+2 \mathrm{TiO}_{2}$ 
Figure 5 reports the solution energies. The most favorable dopant is Ga. Gallium doped LTO has been successfully synthesized by Liang et al. [16], and the improvement in the Li-ion conductivity was reported. Solution energies of $\mathrm{Al}, \mathrm{Co}$, and $\mathrm{Mn}$ are close to that of $\mathrm{Ga}$, suggesting that these dopants are also worth testing experimentally. Solution energy increases with the increase of ionic radius from Ga to Gd. The highest solution energy is calculated for $\mathrm{Gd}$, indicating that this dopant is highly unfavorable.

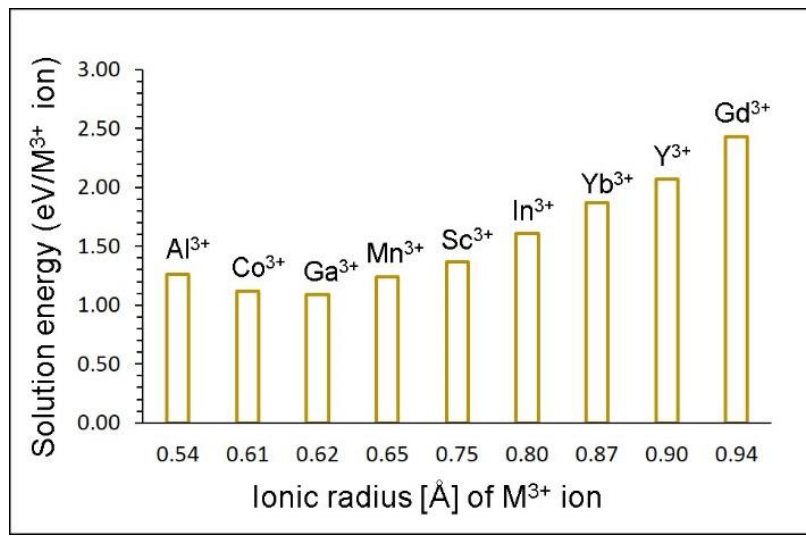

Figure 5. Solution energy of $\mathrm{M}_{2} \mathrm{O}_{3}(\mathrm{M}=\mathrm{Al}, \mathrm{Co}, \mathrm{Ga}, \mathrm{Mn}, \mathrm{Sc}, \mathrm{In}, \mathrm{Yb}, \mathrm{Y}$, and $\mathrm{Gd})$ calculated for the formation of $\mathrm{Li}$ interstitial.

Finally, tetravalent dopants ( $\mathrm{M}=\mathrm{Si}, \mathrm{Ge}, \mathrm{Sn}, \mathrm{Zr}$, and $\mathrm{Ce})$ were considered at the Ti site. The following equation describes this doping process in which no charge compensation is necessary.

$2 \mathrm{MO}+\mathrm{Ti}_{\mathrm{Ti}}^{\mathrm{X}} \rightarrow 2 \mathrm{M}_{\mathrm{Ti}}^{\mathrm{X}}+\mathrm{TiO}_{2}$

Solution energies are reported in Figure 6. The promising dopant for this process is found to be the $\mathrm{Si}$ with the exoergic solution energy of $-1.55 \mathrm{eV}$. The second most favorable dopant is the Ge with the solution energy of $0.81 \mathrm{eV}$. Solution energy increases with the ionic radius. High endothermic solution energies are noted for the other dopants, meaning they are unlikely to dope at normal temperatures.

\section{Conclusions}

In this study, an atomistic simulation study based on the classical pair potentials was used to examine the intrinsic defects, diffusion of Li-ions, the dopant in $\mathrm{LiTi}_{2}\left(\mathrm{PO}_{4}\right)_{3}$. The $\mathrm{Li}$ Frenkel is the lowest energy defect process indicating that both Li vacancies and Li interstitials will be predominant at equilibrium conditions. The low activation energy of $0.36 \mathrm{eV}$ shows that the Li-ion diffusion in these materials is high. It is found that $\mathrm{Na}^{+}$and $\mathrm{Si}^{4+}$ are the prominent isovalent dopants on the $\mathrm{Li}$ and $\mathrm{Ti}$ sites, respectively. $\mathrm{Li}$ interstitials' formation can be facilitated in this material by doping of Ga on the Ti site.

\section{Funding}

This research received no external funding.

\section{Acknowledgments}

Computational facilities and support were provided by High-Performance Computing Centre at Imperial College London and Jaffna University. 


\section{Conflicts of Interest}

The authors declare no conflict of interest.

\section{References}

1. Masquelier, C.; Croguennec, L. Polyanionic (Phosphates, Silicates, Sulfates) Frameworks as Electrode Materials for Rechargeable $\mathrm{Li}$ (or $\mathrm{Na}$ ) Batteries. Chem. Rev. 2013, 113, 6552-6591, https://doi.org/10.1021/cr3001862.

2. Chang, G.; Zhao, Y.; Dong, L.; Wilkinson, D.P.; Zhang, L.; Shao, Q.; Yan, W.; Sun, X.; Zhang, J. A review of phosphorus and phosphides as anode materials for advanced sodium-ion batteries. Journal of Materials Chemistry A 2020, 8, 4996-5048, http://dx.doi.org/10.1039/C9TA12169B.

3. Liu, W.; Zhi, H.; Yu, X. Recent progress in phosphorus based anode materials for lithium/sodium ion batteries. Energy Storage Materials 2019, 16, 290-322, https://doi.org/10.1016/j.ensm.2018.05.020.

4. Ullah, I.; Majid, A.; Khan, M.I. Gadolinium-based olivine phosphate for upgradation of cathode material in lithium ion battery. Journal of Materials Science: Materials in Electronics 2020, 31, 7324-7334, https://doi.org/10.1007/s10854-019-02471-x.

5. Manthiram, A. A reflection on lithium-ion battery cathode chemistry. Nature Communications 2020, 11, 1550, https://doi.org/10.1038/s41467-020-15355-0.

6. Goubard-Bretesché, N.; Kemnitz, E.; Pinna, N. A general low-temperature synthesis route to polyanionic vanadium phosphate fluoride cathode materials: AVPO4F $(\mathrm{A}=\mathrm{Li}, \mathrm{Na}, \mathrm{K})$ and $\mathrm{Na} 3 \mathrm{~V} 2(\mathrm{PO} 4) 2 \mathrm{~F} 3$. Materials Chemistry Frontiers 2019, 3, 2164-2174, http://dx.doi.org/10.1039/C9QM00325H.

7. Zhang, W.-J. Structure and performance of LiFePO4 cathode materials: A review. J. Power Sources 2011, 196, 2962-2970, https://doi.org/10.1016/j.jpowsour.2010.11.113.

8. Islam, M.S.; Driscoll, D.J.; Fisher, C.A.J.; Slater, P.R. Atomic-Scale Investigation of Defects, Dopants, and Lithium Transport in the LiFePO4 Olivine-Type Battery Material. Chem. Mater. 2005, 17, 5085-5092, https://doi.org/10.1021/cm050999v.

9. Fisher, C.A.J.; Hart Prieto, V.M.; Islam, M.S. Lithium Battery Materials LiMPO4 (M = Mn, Fe, Co, and Ni): Insights into Defect Association, Transport Mechanisms, and Doping Behavior. Chem. Mater. 2008, 20, 5907-5915, https://doi.org/10.1021/cm801262x.

10. Fu, Y.; Wei, Q.; Zhang, G.; Sun, S. Advanced Phosphorus-Based Materials for Lithium/Sodium-Ion Batteries: Recent Developments and Future Perspectives. Advanced Energy Materials 2018, 8, 1703058, https://doi.org/10.1002/aenm.201702849.

11. Rui, X.; Yan, Q.; Skyllas-Kazacos, M.; Lim, T.M. Li3V2(PO4)3 cathode materials for lithium-ion batteries: A review. J. Power Sources 2014, 258, 19-38, https://doi.org/10.1016/j.jpowsour.2014.01.126.

12. Kuang, Q.; Xu, J.; Zhao, Y.; Chen, X.; Chen, L. Layered monodiphosphate Li9V3(P2O7)3(PO4)2: A novel cathode material for lithium-ion batteries. Electrochim. Acta 2011, 56, 2201-2205, https://doi.org/10.1016/j.electacta.2010.11.051.

13. Takada, K.; Tansho, M.; Yanase, I.; Inada, T.; Kajiyama, A.; Kouguchi, M.; Kondo, S.; Watanabe, M. Lithium ion conduction in LiTi2(PO4)3. Solid State Ionics 2001, 139, 241-247, https://doi.org/10.1016/S0167-2738(01)00688-9.

14. Nuspl, G.; Takeuchi, T.; Weiß, A.; Kageyama, H.; Yoshizawa, K.; Yamabe, T. Lithium ion migration pathways in LiTi2(PO4)3 and related materials. J. Appl. Phys. 1999, 86, 5484-5491, https://aip.scitation.org/doi/abs/10.1063/1.371550.

15. Lang, B.; Ziebarth, B.; Elsässer, C. Lithium Ion Conduction in LiTi2(PO4)3 and Related Compounds Based on the NASICON Structure: A First-Principles Study. Chem. Mater. 2015, 27, 5040-5048, https://doi.org/10.1021/acs.chemmater.5b01582.

16. Liang, Y.; Peng, C.; Kamiike, Y.; Kuroda, K.; Okido, M. Gallium doped NASICON type LiTi2(PO4)3 thinfilm grown on graphite anode as solid electrolyte for all solid state lithium batteries. J. Alloys Compd. 2019, 775, 1147-1155, https://doi.org/10.1016/j.jallcom.2018.10.226.

17. Kuganathan, N.; Kordatos, A.; Anurakavan, S.; Iyngaran, P.; Chroneos, A. Li3SbO4 lithium-ion battery material: Defects, lithium ion diffusion and tetravalent dopants. Mater. Chem. Phys. 2019, 225, 34-41, https://doi.org/10.1016/j.matchemphys.2018.12.055.

18. Kuganathan, N.; Kordatos, A.; Kelaidis, N.; Chroneos, A. Defects, Lithium Mobility and Tetravalent Dopants in the Li3NbO4 Cathode Material. Sci. Rep. 2019, 9, 2192, https://doi.org/10.1038/s41598-018-37466-x. 
19. Kuganathan, N.; Chroneos, A. Na3V(PO4)2 cathode material for Na ion batteries: Defects, dopants and Na diffusion. Solid State Ionics 2019, 336, 75-79, https://doi.org/10.1016/j.ssi.2019.03.025.

20. Morando, C.; Cofrancesco, P.; Tealdi, C. Zn ion diffusion in spinel-type cathode materials for rechargeable batteries: the role of point defects. Materials Today Communications 2020, 25, 101478, https://doi.org/10.1016/j.mtcomm.2020.101478.

21. Dawson, J.A.; Canepa, P.; Clarke, M.J.; Famprikis, T.; Ghosh, D.; Islam, M.S. Toward Understanding the Different Influences of Grain Boundaries on Ion Transport in Sulfide and Oxide Solid Electrolytes. Chem. Mater. 2019, 31, 5296-5304, https://doi.org/10.1021/acs.chemmater.9b01794.

22. Gale, J.D.; Rohl, A.L. The General Utility Lattice Program (GULP). Mol. Simul. 2003, 29, 291-341, https://doi.org/10.1080/0892702031000104887.

23. Kuganathan, N.; Islam, M.S. Li2MnSiO4 Lithium Battery Material: Atomic-Scale Study of Defects, Lithium Mobility, and Trivalent Dopants. Chem. Mater. 2009, 21, 5196-5202, https://doi.org/10.1021/cm902163k.

24. Olson, C.L.; Nelson, J.; Islam, M.S. Defect Chemistry, Surface Structures, and Lithium Insertion in Anatase TiO2. The Journal of Physical Chemistry B 2006, 110, 9995-10001, https://doi.org/10.1021/jp0572611.

25. Lusvardi, G.; Malavasi, G.; Menabue, L.; Menziani, M.C.; Pedone, A.; Segre, U. A Computational Tool for the Prediction of Crystalline Phases Obtained from Controlled Crystallization of Glasses. The Journal of Physical Chemistry B 2005, 109, 21586-21592, https://doi.org/10.1021/jp0546857.

26. Kovaleva, N.N.; Boris, A.V.; Capogna, L.; Gavartin, J.L.; Popovich, P.; Yordanov, P.; Maljuk, A.; Stoneham, A.M.; Keimer, B. Dipole-active optical phonons in $\mathrm{YTiO}_{3}$ : Ellipsometry study and lattice-dynamics calculations. Physical Review B 2009, 79, 045114, https://link.aps.org/doi/10.1103/PhysRevB.79.045114.

27. Gale, J.D. GULP: A computer program for the symmetry-adapted simulation of solids. J. Chem. Soc., Faraday Trans. 1997, 93, 629-637, http://dx.doi.org/10.1039/A606455H.

28. Mott, N.F.; Littleton, M.J. Conduction in polar crystals. I. Electrolytic conduction in solid salts. Trans. Faraday Society 1938, 34, 485-499, http://dx.doi.org/10.1039/TF9383400485.

29. Grimes, R.W.; Busker, G.; McCoy, M.A.; Chroneos, A.; Kilner, J.A.; Chen, S.-P. The Effect of Ion Size on Solution Mechanism and Defect Cluster Geometry. Berichte der Bunsengesellschaft für physikalische Chemie 1997, 101, 1204-1210, https://doi.org/10.1002/bbpc.199700026.

30. Redhammer, G.J.; Rettenwander, D.; Pristat, S.; Dashjav, E.; Kumar, C.M.N.; Topa, D.; Tietz, F. A single crystal X-ray and powder neutron diffraction study on NASICON-type Li1+xAlxTi2-x(PO4)3 $(0 \leq x \leq 0.5)$ crystals: Implications on ionic conductivity. Solid State Sciences 2016, 60, 99-107, https://doi.org/10.1016/j.solidstatesciences.2016.08.011.

31. Kröger, F.A.; Vink, H.J. Relations between the Concentrations of Imperfections in Crystalline Solids. In Solid State Phys., Seitz, F., Turnbull, D., Eds. Academic Press: 1956; Vol. 3, 307-435, https://doi.org/10.1016/S0081-1947(08)60135-6.

32. Kuganathan, N.; Davazoglou, K.; Chroneos, A. Computer modeling investigation of MgV2O4 for Mg-ion batteries. J. Appl. Phys. 2020, 127, 035106, https://doi.org/10.1063/1.5139114.

33. Case, D.; McSloy, A.J.; Sharpe, R.; Yeandel, S.R.; Bartlett, T.; Cookson, J.; Dashjav, E.; Tietz, F.; Naveen Kumar, C.M.; Goddard, P. Structure and ion transport of lithium-rich Li1 $+x A 1 x T i 2-x(P O 4) 3$ with $0.3<x<0.5$ : A combined computational and experimental study. Solid State Ionics 2020, 346, 115192, https://doi.org/10.1016/j.ssi.2019.115192.

34. Jackson, R.A., Szaller, Z. Recent Progress in Lithium Niobate. Crystals. 2020, 10, 780, https://doi.org/10.3390/cryst10090780.

35. Kuganathan, N.; Ganeshalingam, S.; Chroneos, A. Defect, transport, and dopant properties of andradite garnet Ca3Fe2Si3O12. AIP Advances 2020, 10, 075004, https://doi.org/10.1063/5.0012594.

36. Nishimura, S.-i.; Kobayashi, G.; Ohoyama, K.; Kanno, R.; Yashima, M.; Yamada, A. Experimental visualization of lithium diffusion in LixFePO4. Nature Materials 2008, 7, 707-711, http://dx.doi.org/10.1038/nmat2251. 